\title{
A clinical study of rate and indications of cesarean section, maternal and fetal outcomes at tertiary care center in north western Rajasthan
}

\author{
Suniti Verma ${ }^{1}$, Jyoti Saini ${ }^{2}$, Ramnarayan Sehra ${ }^{3}$, Niranjan Nagaraj ${ }^{4} *$
}

\author{
${ }^{1}$ Department of Obstetrics and Gynaecology, SMS medical college, Jaipur, Rajasthan, India \\ ${ }^{2}$ Medical officer, Medical and Health Department, Rajasthan, India \\ ${ }^{3}$ Department of Paediatrics, SMS medical college, Jaipur, Rajasthan, India \\ ${ }^{4}$ Department of Paediatrics, SP Medical College, Bikaner, Rajasthan, India
}

Received: 21 June 2016

Accepted: 12 July 2016

\author{
*Correspondence: \\ Dr. Niranjan Nagaraj, \\ E-mail: getniranjan806@yahoo.com
}

Copyright: () the author(s), publisher and licensee Medip Academy. This is an open-access article distributed under the terms of the Creative Commons Attribution Non-Commercial License, which permits unrestricted non-commercial use, distribution, and reproduction in any medium, provided the original work is properly cited.

\begin{abstract}
Background: Cesarean section is one of the most commonly performed surgeries in obstetric practice. This study aims to know the changing trends in cesarean section rates, varying indications and the maternal \& fetal outcome of cesarean deliveries.

Methods: Total 200 cases of cesarean section were selected including each of 100 elective and emergency groups. In these we studied and evaluated the various parameters of cesarean section, maternal morbidity, neonatal outcomes, morbidity and mortality.

Results: The commonest indication for emergency cesarean section was MSL (28\%) followed by previous cesarean section (27\%). Mean age in elective cesarean section was $25.43 \pm 2.90$ years and in emergency group it was 24.78 \pm 3.23 . In present study 11 neonates of elective group had NICU admission while 64 neonates of emergency group had NICU admission. Perinatal mortality was present in 15 neonates and out of them 12 emergency groups and 3 belonged to elective group. The commonest indication for elective cesarean section was previous cesarean section (42\%) followed by previous 2LSCS (15\%).

Conclusions: The rate of cesarean section is progressively increasing in the last 5 years. The most common indication is previous cesarean section. The outcome in elective is better than emergency.
\end{abstract}

Keywords: Cesarean section, Maternal morbidity, Perinatal mortality, Neonatal outcome

\section{INTRODUCTION}

Cesarean section is one of the most commonly performed surgeries in obstetric practice. Obstetric practice has witnessed an increasing frequency in cesarean deliveries from $21.8 \%$ to $25.4 \% .^{1}$ Cesarean section significantly reduces maternal and perinatal mortality. The World Health Organization considers cesarean section rate of 5$15 \%$ to be optimal range for targeted provision of this life saving interventions for mother and infant. ${ }^{2}$ According to estimate of WHO;2005, half a million, most of them in developing countries die each year of complications during pregnancy and child birth, one in 6 women who die live in India. ${ }^{3}$ The WHO withdrew its previous recommendation of a $15 \%$ CS rate in June 2010. Their official statement rate, "there is no empirical evidence for an optimum percentage" what matters most is that all women who need cesarean section receive them. ${ }^{4}$

\section{METHODS}

A prospective hospital based study was conducted in the department of Obstetrics and Gynecology, Sardar Patel Medical College, Bikaner, Rajasthan. Total deliveries that took place in the department from Jan 2013 to Dec 2013 were included. Total 200 cases of cesarean section were selected including each of 100 elective and 
emergency groups. In these the various parameters of cesarean section, maternal morbidity, neonatal outcome, morbidity and mortality were evaluated. Cases included were those with gestational age $>37$ wks., booked or unbooked, cases handled outside and referred cases admitted in our hospital for elective cesarean delivery. Excluded were those with gestational age <37 wks., multiple gestation, those with surgical disorders.

\section{RESULTS}

Table 1: Distribution of cases according to neonatal outcome in relation to elective/emergency cesarean section.

\begin{tabular}{|c|c|c|c|c|c|c|}
\hline \multirow{3}{*}{ Neonatal Outcome } & \multicolumn{4}{|c|}{ Elective/Emergency } & \multicolumn{2}{|c|}{ Total } \\
\hline & \multicolumn{2}{|c|}{ Elective } & \multicolumn{2}{|c|}{ Emergency } & \multirow[b]{2}{*}{ No. } & \multirow[b]{2}{*}{$\%$} \\
\hline & No. & $\%$ & No. & $\%$ & & \\
\hline Asphyxia & 3 & 3.0 & 14 & 14.0 & 17 & 8.5 \\
\hline Congenital Malformation & 1 & 1.0 & 2 & 2.0 & 3 & 1.5 \\
\hline Cord Around Neck & 2 & 2.0 & 2 & 2.0 & 4 & 2.0 \\
\hline IUD & 0 & - & 7 & 7.0 & 7 & 3.5 \\
\hline IUD+Hydrocephalous & 0 & - & 1 & 1.0 & 1 & 0.5 \\
\hline IUGR & 0 & - & 1 & 1.0 & 1 & 0.5 \\
\hline Live & 94 & 94.0 & 69 & 69.0 & 163 & 81.5 \\
\hline Still Birth & 0 & - & 4 & 4.0 & 4 & 2.0 \\
\hline Total & 100 & & 100 & & 200 & \\
\hline$X^{2}$ & 24.2 & & & & & \\
\hline $\mathrm{P}$ & 0.00 & & & & & \\
\hline
\end{tabular}

Table 2: Distribution of cases according to intraoperative complications in relation to elective/emergency cesarean section.

\begin{tabular}{|c|c|c|c|c|c|c|}
\hline \multirow{3}{*}{$\begin{array}{l}\text { Intraoperative Complications } \\
\text { /Findings }\end{array}$} & \multicolumn{4}{|c|}{ Elective/Emergency } & \multirow{2}{*}{\multicolumn{2}{|c|}{ Total }} \\
\hline & \multicolumn{2}{|c|}{ Elective } & \multicolumn{2}{|c|}{ Emergency } & & \\
\hline & No. & $\%$ & No. & $\%$ & No. & $\%$ \\
\hline No complications & 72 & 72.0 & 74 & 74.0 & 146 & 74.0 \\
\hline Bicornual & 1 & 1.0 & 0 & - & 1 & 0.5 \\
\hline Complete septa + in uterus & 0 & - & 1 & 1.0 & 1 & 0.5 \\
\hline Dense adhesion & 18 & 18.0 & 4 & 4.0 & 22 & 11.0 \\
\hline $\mathrm{PPH}$ & 2 & 2.0 & 11 & 11.0 & 13 & 6.5 \\
\hline Retro placental clots & 1 & 1.0 & 0 & - & 1 & 0.5 \\
\hline Scar dehiscence & 6 & 6.0 & 10 & 10.0 & 16 & 8.0 \\
\hline Total & 100 & & 100 & & 200 & \\
\hline $\mathrm{X}^{2}$ & 21.168 & & & & & \\
\hline $\mathrm{P}$ & 0.007 & & & & & \\
\hline
\end{tabular}

The commonest indication for emergency cesarean section was MSL (28\%) followed by previous cesarean section $(27 \%)$. Mean age in elective cesarean section was $25.43 \pm 2.90$ years and in emergency group it was 24.78 \pm 3.23 . In present study 11 neonates of elective group had NICU admission while 64 neonates of emergency group had NICU admission.

Perinatal mortality was present in 15 neonates and out of them 12 emergency groups and 3 belonged to elective group. The commonest indication for elective cesarean section was previous cesarean section (42\%) followed by previous 2LSCS (15\%).

\section{DISCUSSION}

During our study period, there were total 14202 deliveries, of which 3028 were cesarean deliveries. The cesarean delivery rate in our hospital was $21.32 \%$. The changing trend of cesarean section is that cesarean section is progressively increasing that is $19.09 \%$ in $2009,19.44 \%$ in $2010,20.7 \%$ in $2011,20.97 \%$ in 2012 , 
and $21.32 \%$ in 2013. Majority of patients in elective group were of $26-30 y r s(51 \%)$ and in emergency group $21-25 y r s(49 \%)$. A study conducted also shown that younger age group $(<25$ yrs $)$ constitute $28.6 \%{ }^{5}$. Every pregnancy whether teen or otherwise has to be considered important as maternal complications cannot be predicted. Most of females were gravida $1(44.5 \%)$ and $2(38 \%)$. Primigravida constitute $52 \%$ of emergency group while second gravida were $44 \%$ of elective group. In a study, the association between low parity and cesarean section was seen statistically significant ${ }^{6}$. In another study conducted, it was also seen that $42.4 \%$ were primigravida in cesarean deliveries in both group. ${ }^{7}$

In a present study, elective cesarean sections were performed in $62 \%$ booked patients while emergency cesarean sections were performed in $75 \%$ of the unbooked patients. The rate of cesarean delivery was 6 times higher in referred cases as compared to booked cases, the reason being lack of proper antenatal and intranatal care. ${ }^{5}$ There was significant difference in the incidence of low birth weight babies in booked and unbooked cases thus utilization of the antenatal services provides a health care package to the women and her baby. The commonest indication for elective cesarean section was previous cesarean section $(42 \%)$ followed by previous 2LSCS (15\%), primi breech (15\%), and CPD (14\%). The commonest indication for emergency cesarean section was MSL $(28 \%)$ followed by previous cesarean section $(27 \%)$, DTA $(9 \%)$, NPOL with PROM $(8 \%)$. In our study overall previous cesarean section $(34.5 \%)$ was the most common indication in total patients. A study also reported previous cesarean (61.5\%) as commonest indication in elective group, whereas failure to progress $(41.5 \%)$ accounted for highest number of cases in emergency group. ${ }^{6}$ In another study commonest indication for elective cesarean delivery was previous cesarean section, pre-eclampsia and APH constituted the frequent indications for emergency cesarean delivery. ${ }^{7}$ In another study, commonest indication for primary section was CPD (29.3\%), Malpresentation (20\%) and obstructed labour (8\%). Among repeat cesarean CPD $(48.38 \%)$ and previous cesarean $(10 \%){ }^{8}$

Majority of patients were operated under spinal anaesthesia $(97 \%)$ as compared to general anaesthesia (3\%). Spinal anaesthesia technique is not difficult. No inhalation anesthesia is required and less fetal hypoxia while with general anaesthesia aspiration of gastric contents is a serious and life threatening one, also uterine contractility may be diminished by volatile agents, hypoxia and hypercapnia may occur. Longer the exposure to GA before delivery the more depressed is the Apgar score. Majority of patients were operated through Pfannensteil incision (68\%) as compared to SUMV incision $(32 \%)$. Pfannensteil incision follow Langer lines of skin tension and thus excellent cosmetic result can be achieved. It offers decreased rates of postoperative pain, fascial wound dehiscence and incisional hernia. whether it is strong and less likely to undergo dehiscence is debated, pfannensteil incision is often discouraged for cases in which a large operating space is essential or in which access to upper abdomen may be required with repeat cesarean delivery re-entry through a pfannensteil incision usually is a time consuming and difficult because of scarring in these cases SUMV incision is performed.

The intraoperative complications encountered in emergency cesarean section were increased incidence of $\mathrm{PPH}$, extended incision, scar dehiscence, dense adhesion as compared to elective cesarean section. A study reported significant intra operative difficulties like fetal head impaction in almost one third of cesarean delivery and greater blood loss. ${ }^{9}$ A study reported hemorrhage $(4.75 \%)$ and uterine incision extension (1.2\%) in emergency cesarean group. ${ }^{6}$ Following cesarean section in obstructed labour, $7.09 \%$ cases had complications like urinary bladder injury, extended incision to uterine arteries and broad ligament hematoma. ${ }^{10} \mathrm{It}$ is common for emergency operation to be undertaken when the patient has been in labour, stretching of lower uterine segment and impaction of presenting part into the pelvic cavity, thereby making the operation bloody. ${ }^{11}$

There was greater incidence of postoperative pyrexia, need for blood transfusion in emergency group as compared to elective group. Blood transfusion required in $18 \%$ of emergency group patients as compared to $10 \%$ of elective group patients. Post-operative febrile illness was present in $85 \%$ of emergency group patients as compared to $62 \%$ of elective group patients. This is inconsistent with other studies. ${ }^{12}$ One maternal mortality occurred in emergency group. A fourth gravida mother with previous cesarean section with ruptured uterus underwent emergency cesarean section. Her urinary bladder was also ruptured. Baby was dead. She was admitted in ICU and expired there on $2^{\text {nd }}$ postoperative day. The cause of death was septicemia with hypovolemic shock. The rest of maternal outcomes were good in both groups. Live births were more in elective group (94\%) as compared to emergency group. Asphyxiated babies were more in emergency group (14\%) as compared to elective group $(3 \%)$. IUD's were $7 \%$ ) and stillbirth $4 \%$ in emergency group. Congenital malformations were also more in emergency group (2\%) as compared to elective group (1\%). When analysed for Apgar scores, in emergency cesarean section, Apgar score at 1 and 5 min was lesser (3 and 5, 5 and 7) as compared to elective cesarean group (7 and 9). A study showed Apgar at 5 minutes to be less favourable in emergency cesarean group; than elective cesarean group. ${ }^{6}$ NICU admission in emergency group was $64 \%$ where as in elective group was $11 \%$. In one study, neonates in elective cesarean group had less frequent asphyxia and less frequent resuscitation than in emergency cesarean group. ${ }^{13}$ Perinatal mortality rate was $3 \%$ as compared to $12 \%$ in emergency group. Most of the deaths occurred in unbooked cases. Eclampsia, APH, birth asphyxia, obstructed labour accounted for more than 
half of deaths. In total 200 patients $16.5 \%$ patients had chosen PPIUCD while $13.5 \%$ had tubal ligation.

\section{CONCLUSION}

The rate of cesarean section is progressively increasing in the last 5 years. The most common indication is previous cesarean section. The outcome in elective is better than emergency.

\section{Funding: No funding sources}

Conflict of interest: None declared

Ethical approval: The study was approved by the Institutional Ethics Committee

\section{REFERENCES}

1. Kambo I, Bedi N, Dhillon BS, Saxena NC. A Critical Appraisal of Cesarean section rates at teaching hospital in India. International J Obstet Gynecol. 2002;79:151-8.

2. Akolekar R, Pandit SN, Rao BS. The cesarean Birth FOGSI publications, $1^{\text {st }}$ Edn. National Book Depot. 2010:1-3.

3. WHO Health statistics 2005, WHO.

4. Focus on: caesarean section - NHS Institute for Innovation and Improvement. Institute.nhs.uk.8 October, 2009.

5. Stark M, Chavkin Y, Kupfersztain C, Guedj P, Finkel AR. Evaluation of combinations of procedures in caesarean saction. Int $\mathbf{J}$ Gynecol Obstet. 1995;48(3):273.
6. Denis C. Fear of Pain causes a bid rise in Caesareans. 26 October 2008. The Guardian. Retrieved 27 October, 2008.

7. Smith S. C-section leap to 1 in 3 births in Bay State, to outstrip US. Boston Globe. 14 February 2008.

8. Arulkumaran S, Ratnam S, Bhaskar rao K: The management of labour. Orient Layman ltd. 1996;4:57-69.

9. Neilson TF, Hokegard KH. Post-operative cesarean section morbidity. A prospective study. Am J Obstet Gynecol. 1983;146(8):911-6.

10. Reddy UM, Bettegowda VR, Dias T, YamadaKushnir T, Ko CW, Willinger M. Term pregnancy: a period of heterogeneous risk for infant mortality. Obstet Gynecol. 2011;117(6):1279-87.

11. Cassady G. Effects of caesarean section on neonatal body water spaces. N Engl J Med. 1971;285:887-91.

12. High infant mortality rate seen with elective Csection. Reuters Health, September 2006. Available from: http://www.medicineonline.com/news/ 12/6008/High-infant-mortality-seen-with-elective-csection.html.

13. Murphy KW. Reducing the complication of cesarean section. Bonnar J (ed) RA. Obstet Gynecol. Churchill livingstone, Edinburgh. 1998;20:141-52.

Cite this article as: Verma S, Saini J, Sehra R, Nagaraj N. A clinical study of rate and indications of cesarean section, maternal and fetal outcomes at tertiary care center in north western Rajasthan. Int J Reprod Contracept Obstet Gynecol 2016;5:2791-4. 